\title{
Tracheostomy for COVID-19 respiratory failure: timing, ventilatory characteristics, and outcomes
}

\author{
Janice L. Farlow ${ }^{1} \wedge$, Pauline K. Park ${ }^{2}$, Michael W. Sjoding ${ }^{3}$, Stephen G. Kay ${ }^{3}$, Ross Blank ${ }^{4}$, \\ Kelly M. Malloy ${ }^{1}$, Laraine Washer ${ }^{5}$, Lena M. Napolitano ${ }^{2}$, Venkatakrishna Rajajee ${ }^{6}$, Michael J. Brenner ${ }^{1,7}$, \\ Steven B. Chinn ${ }^{1 \#}$, Jose De Cardenas, ${ }^{2,3 \#}$
}

${ }^{1}$ Department of Otolaryngology-Head and Neck Surgery, Michigan Medicine, Ann Arbor, MI, USA; ${ }^{2}$ Department of Surgery, Michigan Medicine, Ann Arbor, MI, USA; ${ }^{3}$ Division of Pulmonary and Critical Care, Department of Internal Medicine, Michigan Medicine, Ann Arbor, MI, USA; ${ }^{4}$ Department of Anesthesia, Michigan Medicine, Ann Arbor, MI, USA; ${ }^{5}$ Division of Infectious Diseases, Department of Internal Medicine, Michigan Medicine, Ann Arbor, MI, USA; ${ }^{6}$ Department of Neurosurgery, Michigan Medicine, Ann Arbor, MI, USA; ${ }^{7}$ Global Tracheostomy Collaborative, Raleigh, NC, USA

Contributions: (I) Conception and design: All authors; (II) Administrative support: JL Farlow, SG Kay; (III) Provision of study materials or patients: PK Park, R Blank, KM Malloy, LM Napolitano, V Rajajee, SB Chinn, J De Cardenas; (IV) Collection and assembly of data: JL Farlow, SG Kay; (V) Data analysis and interpretation: All authors; (VI) Manuscript writing: All authors; (VII) Final approval of manuscript: All authors.

\#These authors contributed equally to this work.

Correspondence to: Steven B. Chinn. 1500 E. Medical Center SPC 5312, Ann Arbor, MI 48109, USA. Email: schinn@umich.edu; Jose De Cardenas. 1500 E. Medical Center SPC 5361, Ann Arbor, MI 48109, USA. Email: jdecard@med.umich.edu.

Background: Whereas data from the pre-pandemic era have demonstrated that tracheostomy can accelerate liberation from the ventilator, reduce need for sedation, and facilitate rehabilitation, concerns for healthcare worker safety have led to disagreement on tracheostomy placement in COVID-19 patients. Data on COVID-19 patients undergoing tracheostomy may inform best practices. Thus, we report a retrospective institutional cohort experience with tracheostomy in ventilated patients with COVID-19, examining associations between time to tracheostomy and duration of mechanical ventilation in relation to patient characteristics, clinical course, and survival.

Methods: Clinical data were extracted for all COVID-19 tracheostomies performed at a quaternary referral center from April-July 2020. Outcomes studied included mortality, adverse events, duration of mechanical ventilation, and time to decannulation.

Results: Among 64 COVID-19 tracheostomies (13\% of COVID-19 hospitalizations), patients were 64\% male and $42 \%$ African American, with a median age of 54 (range, 20-89). Median time to tracheostomy was 22 (range, 7-60) days and median duration of mechanical ventilation was 39.4 (range, 20-113) days. Earlier tracheostomy was associated with shortened mechanical ventilation $\left(\mathrm{R}^{2}=0.4, \mathrm{P}<0.01\right)$. Median decannulation time was 35.3 (range, 7-79) days. There was 19\% mortality and adverse events in 45\%, mostly from bleeding in therapeutically anticoagulated patients.

Conclusions: Tracheostomy was associated with swifter liberation from the ventilator and acceptable safety for physicians in this series of critically ill COVID-19 patients. Patient mortality was not increased relative to historical data on acute respiratory distress syndrome (ARDS). Future studies are required to establish conclusions of causality regarding tracheostomy timing with mechanical ventilation, complications, or mortality in COVID-19 patients.

Keywords: Tracheostomy; COVID-19; severe acute respiratory syndrome; coronavirus 2; mechanical ventilation

Submitted Jan 18, 2021. Accepted for publication Apr 29, 2021.

doi: $10.21037 /$ jtd-21-10

View this article at: https://dx.doi.org/10.21037/jtd-21-10

^ ORCID: 0000-0003-1214-4960. 


\section{Introduction}

Patients hospitalized for COVID-19 illness may develop acute respiratory distress syndrome (ARDS) requiring prolonged invasive mechanical ventilation that amid surges may overwhelm intensive care resources $(1,2)$. Since tracheostomy may accelerate ventilator weaning, guidance documents have recommended that decisions regarding timing of tracheostomy should consider institutional demand for ventilators (3); and that allocation decisions should consider ethical tenets, scarce critical care resources (4,5), and survivorship (6). Amid emphasis on possibly unique considerations of COVID-19 and corresponding paradigms for management (7), data are accruing that many acute manifestations and outcomes of severe COVID-19 parallel those of ARDS arising from other pathogens $(8,9)$. Such evidence is prompting a reappraisal of the appropriateness of significantly delaying tracheostomy in patients with COVID-19 (10,11).

While the optimal timing of tracheostomy has long been debated (12-14), the controversy assumed new prominence amid the COVID-19 pandemic $(1,15)$. Balancing the theoretical benefits of earlier tracheostomy and critical care resources versus the potential risks of viral transmission during the aerosolizing tracheostomy procedure (16) have challenged prior commonly accepted practices. Reports of high mortality in mechanically ventilated patients may have resulted in reluctance to perform tracheostomy in patients believed to have a relatively poor prognosis, as seen in New York City (17), the United Kingdom (15), and China (18). Subsequent studies have reported lower mortality in mechanically ventilated patients $(19,20)$. Early data of tracheostomy in COVID-19 patients from Europe demonstrate variability in practice but overall low tracheostomy-related morbidity $(21,22)$. Further outcomes data are required for tracheostomy in COVID-19 patients, including rates of and time to decannulation and successful liberation from mechanical ventilation. Herein, we contribute a description of an additional large single institution cohort of COVID-19 patients from the United States who underwent tracheostomy.

We present the following article in accordance with the STROBE reporting checklist (available at https://dx.doi. org/10.21037/jtd-21-10).

\section{Methods}

Institutional guidelines for placement of tracheostomy were developed in March 2020 (see https://cdn.amegroups.cn/ static/public/jtd-21-10-1.pdf in the supplemental digital content). Tracheostomy was considered for patients with COVID-19 who remained ventilator dependent at 3-week post-intubation. Earlier tracheostomy was gradually allowed based on multidisciplinary discussion of risks and benefits. Tracheostomy was performed via an open or percutaneous approach at bedside, except in cases of concurrently needed operation, history of laryngotracheal stenosis, or high-risk cases based on proceduralist recommendation. Further details on institutional guidelines, tracheostomy technique, personal protective equipment, and infectivity mitigation procedures can be found on the supplemental digital content (see Supplemental Methods).

Clinical data were collected from Michigan Medicine and collaborative medical institutions for overall number of COVID-19 infections, intubations, and tracheostomies performed at Michigan Medicine from April through July 2020. Clinical variables examined included demographics; dates for admission, intensive care, intubation, tracheostomy procedure, subsequent tracheostomy management, and hospital discharge; laboratory studies; duration of mechanical ventilation (liberation defined as no further requirement for positive pressure ventilation for any part of the day); respiratory support requirements prior to and posttracheostomy; Sequential Organ Failure Assessment (SOFA) scores (23) prior to tracheostomy; Charlson Comorbidity Index (24) value during the admission; tracheostomy-related adverse events; and discharge disposition. Tracheostomyrelated adverse events included bleeding, defined as: (I) requiring hemostatic agent, (II) cessation of anticoagulation, (III) blood product transfusion, or (IV) operative management; mucous plugging requiring more than suctioning for clearance; pneumothorax caused or worsened by tracheostomy placement or subsequent management; and desaturation during tracheostomy, defined as $\mathrm{SpO}_{2}<90 \%$ for $>5$ minutes during or up to 60 minutes following the procedure. Study data were collected and managed using REDCap (25) electronic data capture tools hosted at the University of Michigan. The study was conducted in accordance with the Declaration of Helsinki (as revised in 2013). The study was approved by the Institutional Review Board of the University of Michigan (HUM00185123), and individual consent for this retrospective analysis was waived. This study received a determination of exempt status by the Institutional Review Board.

\section{Statistical analysis}

All statistical tests were performed in $\mathrm{R}$ (version 4.0.2), 
Table 1 Cohort demographics

\begin{tabular}{|c|c|}
\hline Characteristic & Value \\
\hline Age, median [range] & 54 [20-89] \\
\hline \multicolumn{2}{|l|}{ Sex, n [\%] } \\
\hline Male & $41[64]$ \\
\hline Female & $23[36]$ \\
\hline \multicolumn{2}{|l|}{ Race/ethnicity, n [\%] } \\
\hline African American & 27 [42] \\
\hline Caucasian & $26[41]$ \\
\hline Asian & $2[3]$ \\
\hline Other/unknown & $9[14]$ \\
\hline Body mass index, median [range] & $33[20-57]$ \\
\hline \multicolumn{2}{|l|}{ VV-ECMO requirement, n [\%] } \\
\hline During hospitalization & $13[20]$ \\
\hline During tracheostomy & $11[11]$ \\
\hline $\begin{array}{l}\text { Sequential Organ Failure Assessment at time of } \\
\text { tracheostomy, median [range] }\end{array}$ & $9[4-14]$ \\
\hline Charlson Comorbidity Index, median [range] & $3[0-12]$ \\
\hline \multicolumn{2}{|l|}{ Comorbidities noted during admission, $\mathrm{n}$ [\%] } \\
\hline Diabetes & $40[63]$ \\
\hline Renal disease & $32[50]$ \\
\hline Chronic pulmonary disease & $21[33]$ \\
\hline Congestive heart failure & $17[27]$ \\
\hline Cerebrovascular disease & $12[19]$ \\
\hline
\end{tabular}

VV-ECMO, veno-venous extracorporeal membrane oxygenation $(n=11)$.

and plots were created with $\mathrm{R}$ package ggplot2 (version 3.3.2). Fishers exact testing and two-tailed $t$-tests were used to compare categorical and continuous variables respectively. For comparison of adverse events by preprocedural respiratory support requirements, samples were dichotomized with a cutoff of PEEP $>10$ representing a high respiratory support requirement. In hospital mortality was also compared by dichotomized groups of high admission D-dimer level (cutoff of $>4$ ) and SOFA score (cutoff of $>6$ ), as suggested by Volo et al. (26). Time-toevent analyses were performed using the Kaplan-Meier method, with censoring by length of follow-up and death. Linear regression was performed to compare time to tracheostomy from intubation with length of mechanical ventilation, with outliers $(\mathrm{SD}>2)$ removed $(\mathrm{n}=2)$. Statistical significance was defined as $\mathrm{P}$ value $<0.05$.

\section{Results}

\section{Patient cohort and tracheostomy placement}

Between April 1 and July 31, 2020, there were 490 patients hospitalized at Michigan Medicine with laboratoryconfirmed COVID-19 infection. Of these patients, 146 (30\%) were intubated, and $113(23 \%)$ died. A total of 64 patients underwent tracheostomy (13\% of hospitalized COVID-19 patients), performed by one of 12 attending proceduralists representing interventional pulmonology, acute care surgery, otolaryngology-head and neck surgery, neurosurgical intensivists, and thoracic surgery. None of the physicians who participated in a tracheostomy procedure - proceduralists, physicians performing bronchoscopy, or anesthesiologists - were diagnosed with COVID-19 within one month of the procedure. Demographics of the tracheostomy cohort are detailed in Table 1 .

Tracheostomy was performed at a median of 22 days (range, 7-60) after the start of mechanical ventilation. There was no significant difference $(\mathrm{P}=0.36)$ between the time to tracheostomy in patients who had the tracheostomy placed while on ECMO (median 21, range, 16-32) and the remainder of the cohort (median 22, range, 7-60). As $\mathrm{PEEP}$ and $\mathrm{FiO}_{2}$ requirements may reflect lung rest settings when a patient is on ECMO, PEEP and $\mathrm{FiO}_{2}$ requirements were only examined for non-ECMO patients. The average (range) $\mathrm{PEEP}$ and $\mathrm{FiO}_{2}$ requirements in the 24 hours prior to tracheostomy were 10 [5-16] and 0.55 [0.30-0.82]. One day after tracheostomy, the average (range) $\mathrm{PEEP}$ and $\mathrm{FiO}_{2}$ requirements were 9.6 [5-16] and $0.47[0.30-1.00]$.

The vast majority of patients $(n=60,94 \%)$ had their tracheostomy placed bedside. There were 38 tracheostomy procedures (59\%) performed percutaneously, and $26(41 \%)$ performed via open technique. All tracheostomy operations during the study period were planned elective procedures, with timing and technique of placement determined by the patient's multidisciplinary care team with guidance from institutional protocols (see https://cdn.amegroups.cn/static/public/jtd-2110-1.pdf in the supplemental digital content).

\section{Duration of mechanical ventilation and time to decannulation}

Median follow-up time for the cohort was 94 days. Duration 


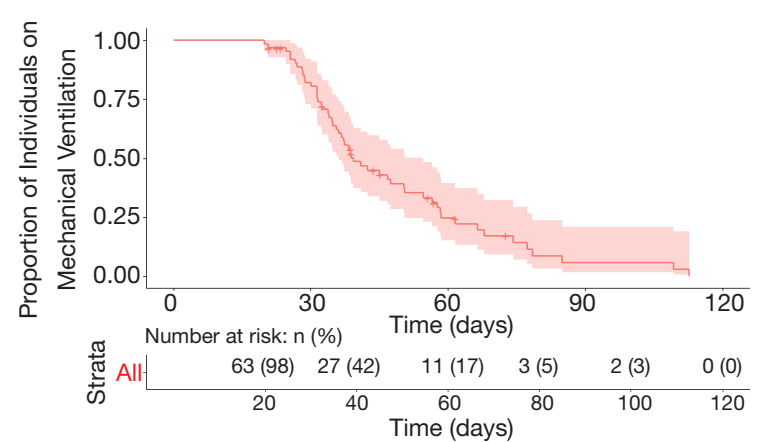

Figure 1 Time-to-event analysis for liberation from mechanical ventilation.

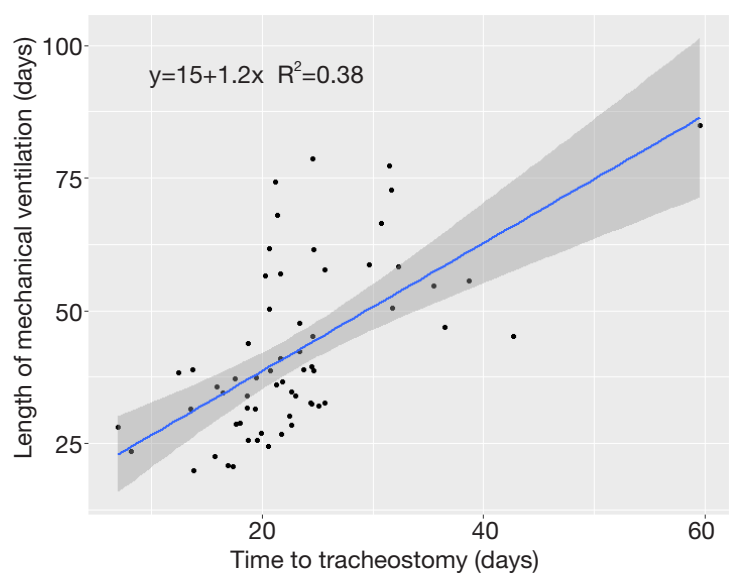

Figure 2 Linear regression model of time to tracheostomy with length of mechanical ventilation as the criterion. $\mathrm{R}^{2}=0.378^{* *}[95 \%$ CI: $0.19,0.52] .{ }^{* *}$ indicates $\mathrm{P}<0.01$.

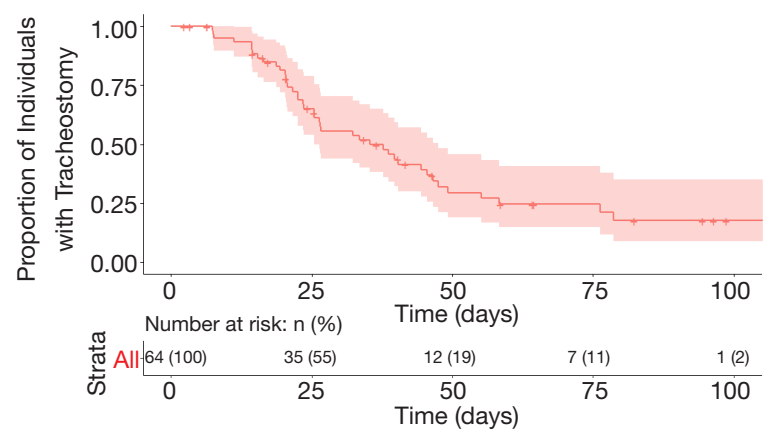

Figure 3 Time-to-event analysis for tracheostomy decannulation.

of mechanical ventilation ranged from 20-113 days, with a censored median liberation from mechanical ventilation time of 39.4 days (Figure 1). There was no statistically significant difference in duration of mechanical ventilation between patients with tracheostomy placement on ECMO (median 50 days, range, 30-109 days) and the remainder of the cohort (median 37 days, range, 20-113 days) $(\mathrm{P}=0.13)$ (see Figure $\mathrm{S} 1$ in the supplemental digital content). A shorter time to tracheostomy was associated with a significantly decreased overall duration of mechanical ventilation $\left(\mathrm{R}^{2}=0.4, \mathrm{P}<0.01\right.$, Figure 2$)$. By this analysis, each additional day to tracheostomy was associated with an incremental addition of 1.2 days to liberation from the ventilator.

Tracheostomy capping was documented in 38 patients at a median of 23 days after tracheostomy (range, 6-61 days). A total of 41 patients were decannulated during the study period, with a censored median decannulation time of 35.3 days (range, 7-79 days) (Figure 3). Of the 12 remaining patients alive with a tracheostomy in place, two had not yet been weaned from mechanical ventilation and were still admitted to Michigan Medicine, five patients were still admitted to a hospital but had been weaned off mechanical ventilation, four had been discharged to long-term care facilities, and one was discharged home. There was a trend of earlier decannulation with percutaneous tracheostomy as compared to an open technique $(\mathrm{P}=0.08)$ (see Figure $\mathrm{S} 2$ in the supplemental digital content); no other clinical variables showed trends toward earlier time to decannulation. Similarly, there was no difference between patients with tracheostomy placement on ECMO and the remainder of the cohort in terms of time to decannulation $(\mathrm{P}=0.32)$ (see Figure $\mathrm{S} 3$ in the supplemental digital content).

\section{Morbidity and mortality}

During the study period, a total of 12 patients in the cohort (19\%) died. All patients who died had a tracheostomy in place except for a patient who experienced a cardiac arrest 4 weeks after tracheostomy decannulation. No deaths in the cohort were attributed to the tracheostomy. Two patients died within 5 days of the procedure, with both cases attributed to underlying disease. One of these patients developed septic shock attributed to his pneumonia two days following tracheostomy placement. The other patient developed acute myocardial dysfunction four days after tracheostomy. No association between in hospital mortality and admission $\mathrm{D}$-dimer level $(\mathrm{P}=0.75)$ and SOFA score $(\mathrm{P}=0.19)$ was identified on univariate testing.

The overall rate of patients experiencing an adverse event was $45 \%$ (Table 2). The breakdown of adverse events was 20 patients who had one event, 7 patients with two events, and 
Table 2 Tabulated complications in the cohort

\begin{tabular}{|c|c|c|c|c|}
\hline \multirow[t]{2}{*}{ Complication } & \multicolumn{2}{|c|}{ All patients $(n=64)$} & \multicolumn{2}{|c|}{$\begin{array}{l}\text { Patients with tracheostomy placed on VV- } \\
\qquad \text { ECMO }(n=11)\end{array}$} \\
\hline & Number of patients & Percentage (\%) & Number of patients & Percentage (\%) \\
\hline Local hemostatic agent and pressure only & 2 & 10 & 0 & 0 \\
\hline Operative hemorrhage control & 1 & 5 & 0 & 0 \\
\hline Mucous plug ${ }^{\ddagger}$ & 7 & 11 & 1 & 9 \\
\hline Pneumothorax ${ }^{\S}$ & 2 & 3 & 0 & 0 \\
\hline Vocal fold paresis & 2 & 3 & 0 & 0 \\
\hline
\end{tabular}

VV-ECMO, veno-venous extracorporeal membrane oxygenation $(n=11){ }^{\dagger}$, bleeding requiring intervention as further listed in the table above. Of the patients experiencing a bleeding complication, 8 patients (38\%) were on extracorporeal membrane oxygenation during and following their tracheostomy placement; ${ }^{\ddagger}$, documented mucous plugging event of tracheostomy requiring more than suctioning for plug clearance. Each case was reviewed by a second physician and determined to not be associated with the tracheostomy procedure itself, i.e., presented in a delayed fashion, and due to underlying tenacious secretions notable in most COVID-19 patients; ${ }^{\S}$, pneumothorax caused by or worsened by tracheostomy placement or management; ", desaturation during tracheostomy, i.e., $\mathrm{SpO}_{2}<90 \%$ for $>5$ minutes during or up to 60 minutes following the tracheostomy.

2 patients with three events. Bleeding was the most common adverse event in the overall cohort $(n=21,33 \%)$. Bleeding was significantly more common $(\mathrm{P}=0.003)$ in patients who had a tracheostomy placed on ECMO $(n=8,73 \%)$ versus the remainder of the cohort $(\mathrm{n}=13,25 \%)$. The majority of patients were on therapeutic anticoagulation $(n=51,80 \%)$ or prophylactic anticoagulation $(\mathrm{n}=12,19 \%)$; all patients with tracheostomy-related bleeding complications were on therapeutic anticoagulation. No significant differences in complication rates were identified between patients who had a high $(>10)$ versus low $(\leq 10)$ pre-tracheostomy PEEP requirement.

\section{Discussion}

In this series, tracheostomy was safely performed in the setting of COVID-19 infection despite high pre-procedural respiratory support requirements. We found that longer time to tracheostomy was associated with increased length of mechanical ventilation. To our knowledge, this study is one of the larger well-characterized institutional case series on tracheostomy in COVID-19 patients, and one of the few to include ECMO patients. Herein, we provide a detailed description of the rates of, and time to, liberation from mechanical ventilation and subsequent decannulation.

\section{Comparison to other cohorts}

Benito et al. recently published a systematic review of tracheostomy for COVID-19, which demonstrates increasing but scattered data on this subject (27). The review includes four studies of comparable size, all of which had a significant percentage of patients still on mechanical ventilation (range, $24-52 \%)(21,22,28,29)$. The percentage of these cohorts still on the ventilator mirrors two more recent publications $(30,31)$. In contrast, due to the longer duration of follow-up in the current study, 97\% of our patients had either been liberated from mechanical ventilation or died. Rovira et al. were able to also follow their United Kingdom cohort for a similar duration of time (32); importantly, our study differs in that our cohort includes ECMO patients. Finally, Avilés-Jurado et al. 
published a smaller well-characterized cohort from Spain that also followed patients longer (33); in contrast to their study, our study applies a time-to-event analysis to duration of mechanical ventilation, rather than defining an early/late tracheostomy cutoff.

\section{Duration of mechanical ventilation and time to tracheostomy}

We found a median duration of mechanical ventilation of 39.4 days, which is longer than other cohorts $(32,33)$. Importantly, however, our study includes a significant number of patients on ECMO, which reflects underlying disease severity and often is associated with prolonged mechanical ventilation (34). While there was no statistically significant difference between duration of ventilation in our ECMO and non-ECMO cohorts, it is likely that our number of patients with tracheostomy placed on ECMO was too small to detect a difference. Furthermore, as a quaternary referral center, a large number of our patients were transferred from other hospitals; ventilator days at these other institutions were factored into our calculations.

The 64 tracheostomy procedures in this cohort represented $13 \%$ of intubated COVID-19 patients at our institution during the study period, as compared to published tracheostomy rates of $10-46 \%(1,26,35)$. A recent multinational survey revealed an average time to tracheostomy of 14 days in COVID-19 patients (1), with other institutional case series reporting a median of 9-24 days $(21,22,26,29,30,35-37)$. Our median time to tracheostomy of 22 days was at the later end of the spectrum, in keeping with our institutional recommendations (see https://cdn. amegroups.cn/static/public/jtd-21-10-1.pdf in the supplemental digital content) and early national guidelines (38).

Outside of the COVID-19 pandemic, a meta-analysis found that early tracheostomy ( $<10$ days $)$ was associated with decreased duration of intensive care (39). We found an association between shorter time to tracheostomy and decreased duration of mechanical ventilation (Figure 2), in keeping with the results of the pre-pandemic TracMan trial (40). In our study, each additional day to tracheostomy was associated with an incremental addition of 1.2 days to liberation from the ventilator. Even a small decrease in need for mechanical ventilation or intensive care per patient could be meaningful during a pandemic with limited critical care resources (4). This must be balanced with increased consumption of personal protective equipment and testing supplies, as well as increased healthcare worker exposure during the procedure itself (41).

\section{Tracheostomy-associated morbidity and mortality}

The mortality of $19 \%$ in this series compares favorably to historical data showing a mortality rate closer to $40 \%$ in patients with pre-COVID-19 ARDS $(42,43)$, as well as mortality rates for COVID-19 patients admitted to intensive care (25-54\%) and other COVID-19 tracheostomy cohorts $(21,26,27)$. Furthermore, no deaths in our case series were directly attributable to tracheostomy placement.

While the mortality rate of our cohort was low, our adverse event rate of $45 \%$ was higher than previous publications $(21,22)$. Most notably, a third required intervention for tracheal bleeding (Table 2). The majority of these ( $86 \%$ of patients with bleeding) met the definition of bleeding because of the need to hold therapeutic anticoagulation. As the thrombotic nature of COVID-19 has been further elucidated (44), practice has shifted toward therapeutic anticoagulation for the critically ill (45). Our series likely represents a later phase of the pandemic than previous reports and thus had a higher rate of therapeutically anticoagulated patients (80\%). Additionally, a large portion of our cohort (20\%) required full anticoagulation for ECMO, which notably has a reported $40 \%$ historical rate of requiring blood product transfusion in the first 48 hours after tracheostomy (34).

\section{Selection of patients for tracheostomy}

Some groups have advocated for prioritizing tracheostomy for patients based on pre-tracheostomy disease severity (26). A multivariate analysis of mortality in COVID-19 tracheostomy patients in a retrospective cohort of 23 patients demonstrated association of both SOFA score $>6$ and D-dimer level $>4$ with a higher risk of death, and thus the authors recommended delaying or not pursuing tracheostomy in these patients (26). In our cohort, no association between these scores and in hospital mortality was identified. All-cause mortality is certainly multifactorial and will require data from the multicenter studies for further delineation in COVID-19 tracheostomy patients.

Given the high pre-procedural respiratory support requirements in our cohort, we also examined whether complications would be more likely in patients with a PEEP $>10$. Higher mechanical support requirements reflect poor lung compliance, which contributes to the known high baseline incidence of perioperative pulmonary 
complications in COVID-19 patients (46). Additionally, higher respiratory support requirements may be a marker for poorer prognosis. We found that tracheostomy could be safely performed in patients despite high respiratory support requirements in our case series. Furthermore, we observed no association of complications with pre-tracheostomy high respiratory support parameters.

\section{Limitations}

This study has several limitations inherent in singleinstitution retrospective case series. The design precludes any inferences of causality regarding timing of tracheostomy and endpoints, such as duration of mechanical ventilation, complications, or mortality. While the association of earlier tracheostomy with shorter duration of mechanical ventilation is consistent with the results of the TracMan trial (40), selection bias is likely. For example, delays in tracheostomy may be necessary in sicker patients requiring a higher level of ventilator support or a function of transfers from outside institutions. Secondly, as a large referral hospital with ECMO services, our experience may not be generalizable to other clinical settings. Additionally, long-term outcomes for these patients, including full decannulation rates, delayed laryngotracheal complications of intubation or tracheostomy, and final mortality statistics cannot be described in this early report. Despite these limitations, this institutional experience is among the first to provide longerterm detailed data on rates of liberation from mechanical ventilation and subsequent decannulation of COVID-19 patients who undergo tracheostomy at different time points.

\section{Conclusions}

In conclusion, we find that tracheostomy can be safely performed in COVID-19 patients, including those on ECMO, and may be associated with decreased duration of mechanical ventilation.

\section{Acknowledgments}

Funding: This work was supported by the National Institutes of Health [K01 HL136687 to MWS and SGK, 1K08CA226350-01A1 to SBC]; and the Michigan Institute for Clinical and Health Research [UL1TR002240].

\section{Footnote}

Reporting Checklist: The authors have completed the STROBE reporting checklist. Available at https://dx.doi. org/10.21037/jtd-21-10

Data Sharing Statement: Available at https://dx.doi. org/10.21037/jtd-21-10

Peer Review File: Available at https://dx.doi.org/10.21037/jtd21-10

Conflicts of Interest: All authors have completed the ICMJE uniform disclosure form (available at https://dx.doi. org/10.21037/jtd-21-10). PKP reports receiving funding paid to her institution during the past three years from the National Institutes of Health, Department of Defense, Eli Lilly, Atox Bio, the Marcus Foundation, and Bristol Myers Squibb; additionally, she serves on the Council of the Society of Critical Care Medicine. MWS, SGK, and SBC are supported by the National Institutes of Health. MJB serves as President and member of the Board of Directors, both of which are volunteer positions, for the Global Tracheostomy Collaborative. The other authors have no conflicts of interest to declare.

Ethical Statement: The authors are accountable for all aspects of the work in ensuring that questions related to the accuracy or integrity of any part of the work are appropriately investigated and resolved. The study was conducted in accordance with the Declaration of Helsinki (as revised in 2013). The study was approved by the Institutional Review Board of the University of Michigan (HUM00185123), and individual consent for this retrospective analysis was waived.

Open Access Statement: This is an Open Access article distributed in accordance with the Creative Commons Attribution-NonCommercial-NoDerivs 4.0 International License (CC BY-NC-ND 4.0), which permits the noncommercial replication and distribution of the article with the strict proviso that no changes or edits are made and the original work is properly cited (including links to both the formal publication through the relevant DOI and the license). See: https://creativecommons.org/licenses/by-nc-nd/4.0/. 


\section{References}

1. D'Souza A, Simo R, D'Souza A, et al. Tracheostomy intervention in intubated COVID positive patients: A survey of current clinical practice among ENT surgeons. Head Neck 2020;42:1382-5.

2. Petrilli CM, Jones SA, Yang J, et al. Factors associated with hospital admission and critical illness among 5279 people with coronavirus disease 2019 in New York City: prospective cohort study. BMJ 2020;369:m1966.

3. Michetti CP, Burlew CC, Bulger EM, et al. Performing tracheostomy during the Covid-19 pandemic: guidance and recommendations from the Critical Care and Acute Care Surgery Committees of the American Association for the Surgery of Trauma. Trauma Surg Acute Care Open 2020;5:e000482.

4. Emanuel EJ, Persad G, Upshur R, et al. Fair Allocation of Scarce Medical Resources in the Time of Covid-19. N Engl J Med 2020;382:2049-55.

5. Truog RD, Mitchell C, Daley GQ. The Toughest Triage - Allocating Ventilators in a Pandemic. N Engl J Med 2020;382:1973-5.

6. Hosey MM, Needham DM. Survivorship after COVID-19 ICU stay. Nat Rev Dis Primers 2020;6:60.

7. Marini JJ, Gattinoni L. Management of COVID-19 Respiratory Distress. JAMA 2020;323:2329-30.

8. Prescott HC, Girard TD. Recovery From Severe COVID-19: Leveraging the Lessons of Survival From Sepsis. JAMA 2020;324:739-40.

9. Rose MR, Hiltz KA, Stephens RS, et al. Novel viruses, old data, and basic principles: how to save lives and avoid harm amid the unknown. Lancet Respir Med 2020;8:661-3.

10. McGrath BA, Brenner MJ, Warrillow SJ, et al. Tracheostomy in the COVID-19 era: global and multidisciplinary guidance. Lancet Respir Med 2020;8:717-25.

11. Schultz MJ, Teng MS, Brenner MJ. Timing of Tracheostomy for Patients With COVID-19 in the ICUSetting Precedent in Unprecedented Times. JAMA Otolaryngol Head Neck Surg 2020;146:887-8.

12. Freeman BD, Borecki IB, Coopersmith CM, et al. Relationship between tracheostomy timing and duration of mechanical ventilation in critically ill patients. Crit Care Med 2005;33:2513-20.

13. Marsh HM, Gillespie DJ, Baumgartner AE. Timing of tracheostomy in the critically ill patient. Chest 1989;96:190-3.

14. Wang F, Wu Y, Bo L, et al. The timing of tracheotomy in critically ill patients undergoing mechanical ventilation: a systematic review and meta-analysis of randomized controlled trials. Chest 2011;140:1456-65.

15. Takhar A, Walker A, Tricklebank S, et al. Recommendation of a practical guideline for safe tracheostomy during the COVID-19 pandemic. Eur Arch Otorhinolaryngol 2020;277:2173-84.

16. Murthy S, Gomersall CD, Fowler RA. Care for Critically Ill Patients With COVID-19. JAMA 2020;323:1499-500.

17. Richardson S, Hirsch JS, Narasimhan M, et al. Presenting Characteristics, Comorbidities, and Outcomes Among 5700 Patients Hospitalized With COVID-19 in the New York City Area. JAMA 2020;323:2052-9.

18. Guan WJ, Ni ZY, Hu Y, et al. Clinical Characteristics of Coronavirus Disease 2019 in China. N Engl J Med 2020;382:1708-20.

19. Auld SC, Caridi-Scheible M, Blum JM, et al. ICU and Ventilator Mortality Among Critically Ill Adults With Coronavirus Disease 2019. Crit Care Med 2020;48:e799-e804.

20. Vahidy FS, Drews AL, Masud FN, et al. Characteristics and Outcomes of COVID-19 Patients During Initial Peak and Resurgence in the Houston Metropolitan Area. JAMA 2020;324:998-1000.

21. Martin-Villares C, Perez Molina-Ramirez C, BartolomeBenito M, et al. Outcome of 1890 tracheostomies for critical COVID-19 patients: a national cohort study in Spain. Eur Arch Otorhinolaryngol 2021;278:1605-12.

22. Tornari C, Surda P, Takhar A, et al. Tracheostomy, ventilatory wean, and decannulation in COVID-19 patients. Eur Arch Otorhinolaryngol 2021;278:1595-604.

23. Vincent JL, Moreno R, Takala J, et al. The SOFA (Sepsisrelated Organ Failure Assessment) score to describe organ dysfunction/failure. On behalf of the Working Group on Sepsis-Related Problems of the European Society of Intensive Care Medicine. Intensive Care Med 1996;22:707-10.

24. Charlson ME, Pompei P, Ales KL, et al. A new method of classifying prognostic comorbidity in longitudinal studies: development and validation. J Chronic Dis 1987;40:373-83.

25. Harris PA, Taylor R, Minor BL, et al. The REDCap consortium: Building an international community of software platform partners. J Biomed Inform 2019;95:103208.

26. Volo T, Stritoni P, Battel I, et al. Elective tracheostomy during COVID-19 outbreak: to whom, when, how? Early experience from Venice, Italy. Eur Arch Otorhinolaryngol 
2021;278:781-9.

27. Benito DA, Bestourous DE, Tong JY, et al. Tracheotomy in COVID-19 Patients: A Systematic Review and Metaanalysis of Weaning, Decannulation, and Survival. Otolaryngol Head Neck Surg 2021. [Epub ahead of print]. doi: 10.1177/0194599820984780.

28. Angel L, Kon ZN, Chang SH, et al. Novel Percutaneous Tracheostomy for Critically Ill Patients With COVID-19. Ann Thorac Surg 2020;110:1006-11.

29. COVIDTrach collaborative. COVIDTrach; the outcomes of mechanically ventilated COVID-19 patients undergoing tracheostomy in the UK: Interim Report. Br J Surg 2020;107:e583-4.

30. Kwak PE, Connors JR, Benedict PA, et al. Early Outcomes From Early Tracheostomy for Patients With COVID-19. JAMA Otolaryngol Head Neck Surg 2021;147:239-44.

31. Long SM, Chern A, Feit NZ, et al. Percutaneous and Open Tracheostomy in Patients with COVID-19: Comparison and Outcomes of an Institutional Series in New York City. Ann Surg 2021;273:403-9.

32. Rovira A, Tricklebank S, Surda P, et al. Open versus percutaneous tracheostomy in COVID-19: a multicentre comparison and recommendation for future resource utilisation. Eur Arch Otorhinolaryngol 2021;278:2107-14.

33. Avilés-Jurado FX, Prieto-Alhambra D, GonzalezSanchez N, et al. Timing, Complications, and Safety of Tracheotomy in Critically Ill Patients With COVID-19. JAMA Otolaryngol Head Neck Surg 2020;147:1-8.

34. Salna M, Tipograf Y, Liou P, et al. Tracheostomy Is Safe During Extracorporeal Membrane Oxygenation Support. ASAIO J 2020;66:652-6.

35. Turri-Zanoni M, Battaglia P, Czaczkes C, et al. Elective Tracheostomy During Mechanical Ventilation in Patients Affected by COVID-19: Preliminary Case Series From Lombardy, Italy. Otolaryngol Head Neck Surg 2020;163:135-7.

36. Floyd E, Harris SS, Lim JW, et al. Early Data From Case

Cite this article as: Farlow JL, Park PK, Sjoding MW, Kay SG, Blank R, Malloy KM, Washer L, Napolitano LM, Rajajee V, Brenner MJ, Chinn SB, De Cardenas J. Tracheostomy for COVID-19 respiratory failure: timing, ventilatory characteristics, and outcomes. J Thorac Dis 2021;13(7):4137-4145. doi: $10.21037 /$ jtd-21-10
Series of Tracheostomy in Patients With SARS-CoV-2. Otolaryngol Head Neck Surg 2020;163:1150-2.

37. Murphy P, Holler E, Lindroth H, et al. Short-term Outcomes for Patients and Providers After Elective Tracheostomy in COVID-19-Positive Patients. J Surg Res 2021;260:38-45.

38. Givi B, Schiff BA, Chinn SB, et al. Safety

Recommendations for Evaluation and Surgery of the Head and Neck During the COVID-19 Pandemic. JAMA Otolaryngol Head Neck Surg 2020;146:579-84.

39. Andriolo BN, Andriolo RB, Saconato H, et al. Early versus late tracheostomy for critically ill patients. Cochrane Database Syst Rev 2015;1:CD007271.

40. Young D, Harrison DA, Cuthbertson BH, et al. Effect of early vs late tracheostomy placement on survival in patients receiving mechanical ventilation: the TracMan randomized trial. JAMA 2013;309:2121-9.

41. Pandian V, Morris LL, Brodsky MB, et al. Critical care guidance for tracheostomy care during the COVID-19 pandemic: a global, multidisciplinary approach. Am J Crit Care 2020;29:e116-27.

42. Lewis SR, Pritchard MW, Thomas CM, et al. Pharmacological agents for adults with acute respiratory distress syndrome. Cochrane Database Syst Rev 2019;7:CD004477.

43. Fowler RA, Lapinsky SE, Hallett D, et al. Critically ill patients with severe acute respiratory syndrome. JAMA 2003;290:367-73.

44. Gupta A, Madhavan MV, Sehgal K, et al. Extrapulmonary manifestations of COVID-19. Nat Med 2020;26:1017-32.

45. Miesbach W, Makris M. COVID-19: Coagulopathy, Risk of Thrombosis, and the Rationale for Anticoagulation. Clin Appl Thromb Hemost 2020;26:1076029620938149.

46. COVIDSurg Collaborative. Mortality and pulmonary complications in patients undergoing surgery with perioperative SARS-CoV-2 infection: an international cohort study. Lancet 2020;396:27-38. 


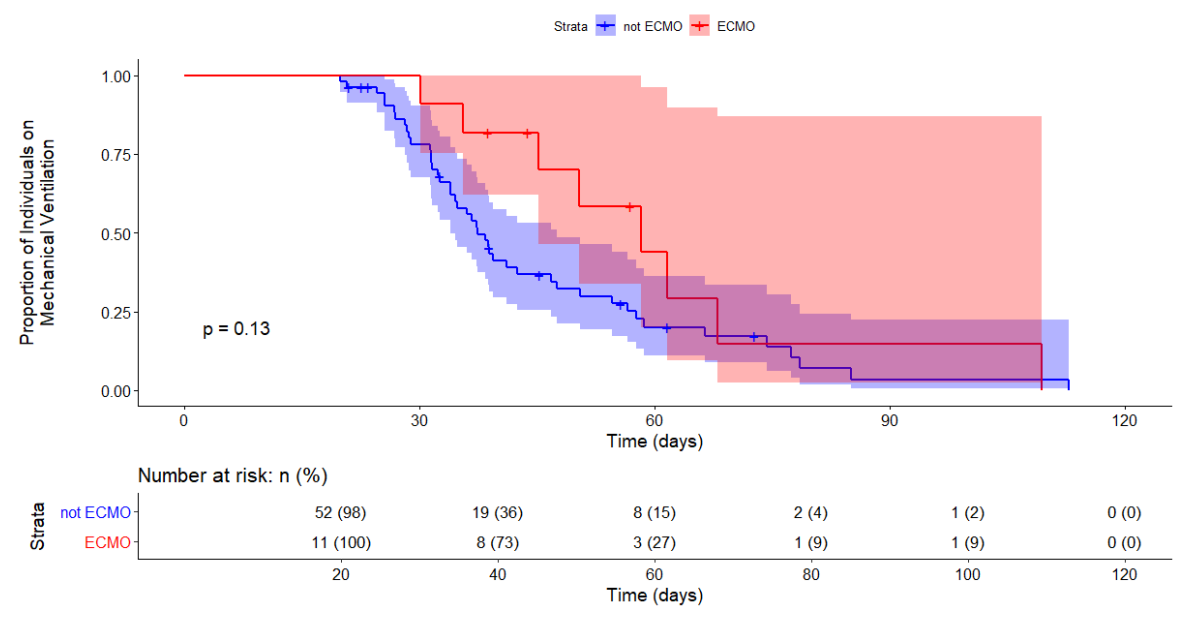

Figure S1 Time-to-event analysis for duration of mechanical ventilation by whether tracheostomy was performed on extracorporeal membrane oxygenation (ECMO).

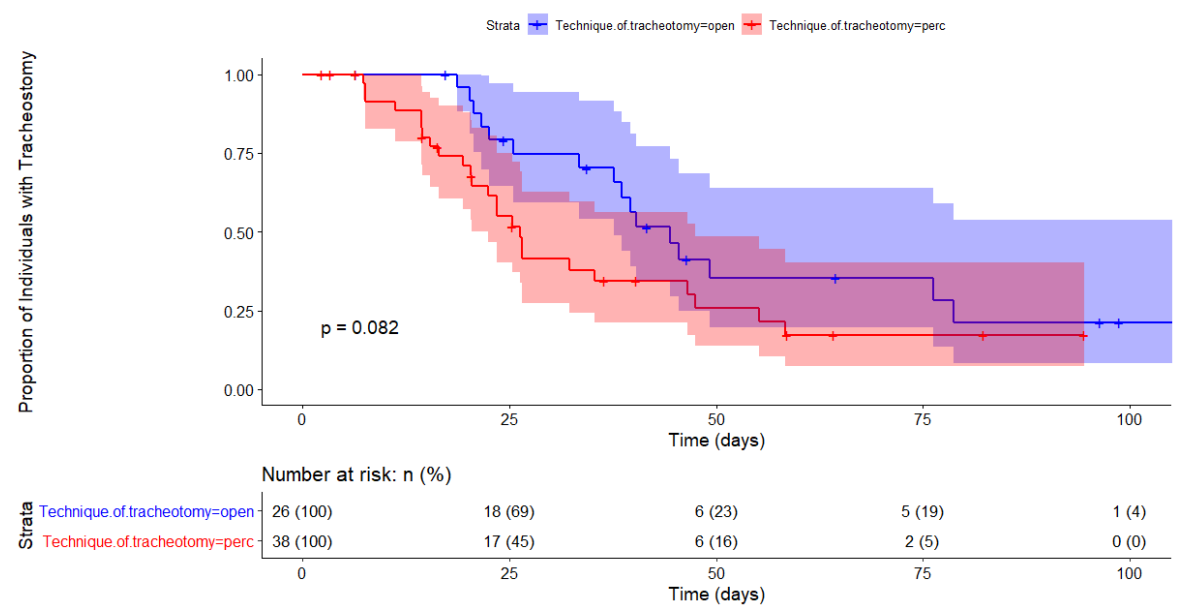

Figure S2 Time-to-event analysis for tracheostomy decannulation by tracheostomy technique. 


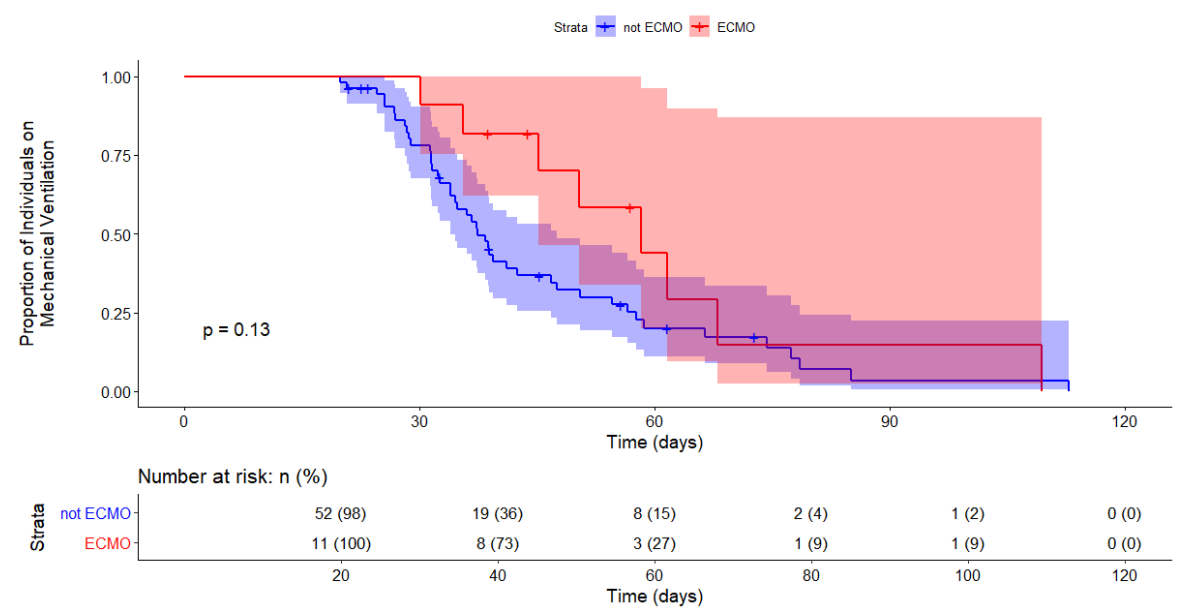

Figure S3 Time-to-event analysis for tracheostomy decannulation by whether tracheostomy was performed on extracorporeal membrane oxygenation (ECMO). 